\title{
A inserção de crianças com transtorno do espectro autista (TEA) no con- texto escolar, familiar e social
}

The insertion of children with autism spectrum disorder (ASDs) in the school, family and social context

La inserción de los niños con trastorno del espectro autista (TEA) en el contexto escolar, familiar y social

\author{
Julia Munhos Partykal', Eduardo Marçal Garcia",
}

\section{Ludmila Lopes Maciel Bolsoni"', Maria Fernanda Piffer Tomasi Baldez da Silva'v}

'Acadêmica do quarto ano da graduação de Medicina da Universidade Cesumar (UniCesumar) de Maringá-PR. Atualmente, diretora geral do departamento de pesquisa da Liga Acadêmica Maringaense de Angiologia e Cirurgia Vascular (LAMACIV) e membro da Liga Acadêmica de Oftalmologia e Otorrinolaringologia de Maringá (LAOOM).

"Acadêmico do quarto ano da graduação de Medicina Universidade Cesumar (UniCesumar) de Maringá-PR. Atualmente, diretor de pesquisa da Liga Acadêmica de Cirurgia Geral e Anestesiologia de Maringá (LACGAM)

e membro da Liga Acadêmica Maringaense de Angiologia e Cirurgia Vascular (LAMACIV).

II' Docente/adjunto do curso de Medicina Centro Universitário de Maringá - UniCesumar.

IV Docente do curso de Medicina Centro Universitário de Maringá - UniCesumar.

\section{RESUMO}

Este artigo teve como objetivo geral investigar a inserção da criança com Transtorno do Espectro Autista (TEA) na escola, família e sociedade. Os objetivos específicos foram indagar sobre a relação da criança autista com os professores e colegas de classe, perguntar a respeito da relação da criança autista com a família e cuidadores e questionar sobre o relacionamento da criança autista com a sociedade em geral. A metodologia incluiu um questionário para pais ou cuidadores em relação à percepção deles para com as crianças autistas quanto às dificuldades comunicativas. Os principais resultados obtidos foram sobre a sociedade possuir poucas informações de como se relacionar socialmente com um indivíduo autista, além de que as pessoas muitas vezes estranham ou evitam as crianças com TEA.

Palavras-chave: Inclusão social do autista. Autismo no ambiente familiar. Autismo no ambiente escolar. Dificuldade comunicativa do autista. 


\section{ABSTRACT}

The general objective of this article was to investigate the integration of the child with Autistic Spectrum Disorder (ASD) in school, family and society. The specific objectives were to inquire about the autistic child's relationship with teachers and classmates, to ask about the relationship of the autistic child with family and caregivers, and to inquire about the relationship of the autistic child with society in general. The methodology included a questionnaire for parents or caregivers regarding their perception towards autistic children about communication difficulties. The main results obtained were that society has little information on how to socially relate to an autistic individual, besides that people often find children with ASD strange or avoid them.

Keywords: Social inclusion of the autistic. Autism in the family environment. Autism in the school environment. Communicative difficulty of the autistic.

\section{RESUMÉN}

Este artículo tuvo como objetivo investigar la inserción de niños con Trastorno del Espectro Autista (TEA) en la escuela, la familia y la sociedad. Los objetivos específicos fueron indagar sobre la relación interpersonal del niño autista con los profesores y compañeros de clase, preguntar sobre la relación del niño autista con la familia y los cuidadores, y cuestionar la relación del niño autista con la sociedad en general. La metodología incluyó un cuestionario para padres o cuidadores en relación con su percepción de los niños autistas sobre dificultades comunicativas. Los principales resultados obtenidos fueron que la sociedad tiene poca información sobre cómo relacionarse socialmente con un individuo autista, además del hecho de que las personas a menudo lo encuentran extraño o evitan a los niños con TEA.

Palabras clave: Inclusión social de autistas. Autismo en el entorno familiar. Autismo en el entorno escolar. Dificultad comunicativa del autista.

\section{INTRODUÇÃO}

O Transtorno do Espectro Autista (TEA) inclui um grupo fenotipicamente distinto de síndromes neuroevolutivas com hereditariedade poligênica e é considerado um dos transtornos do neurodesenvolvimento mais prevalentes na infância. Segundo a $5^{a}$ edição do Manual Diagnóstico e Estatístico de Transtornos Mentais (DSM-V), os critérios de diagnóstico para TEA incluem dificuldades de comunicação social e comportamentos restritos e repetitivos (estereotipias) (SADOCK, 2017).

\subsection{Epidemiologia}


O autismo é um dos transtornos globais do desenvolvimento de maior relevância devido a sua alta prevalência. Estimativas de dados epidemiológicos mundiais indicam que um a cada 88 nascidos vivos apresenta TEA, acometendo mais o sexo masculino. Em 2010, contabilizou-se cerca de 500 mil pessoas autistas no Brasil (GOMES et al., 2015).

Nos anos 2000 , foi diagnosticada uma taxa de $0,7 \%$ de crianças autistas nos Estados Unidos. Em 2015, foi estimado que indivíduos com TEA abrangia cerca de 24,8 milhões de pessoas no mundo. Já em 2017, em países desenvolvidos, aproximadamente, $1,5 \%$ das crianças foram diagnosticadas com TEA. Há uma correlação em países desenvolvidos de que maiores recursos financeiros para o tratamento do autismo estão ligados a um aumento no diagnóstico do transtorno (CRITTENDEN, 2017; LYALL et al., 2017).

Além disso, a chance de o irmão de uma criança autista também ser afetado é 20 vezes maior, tendo uma prevalência de 10,1\%. Se já houver dois irmãos com o transtorno, a probabilidade do terceiro irmão também ser autista chega a $25 \%$. O risco de recorrência do autismo em um familiar de autista é consideravelmente maior que na população geral (SWAIMAN et al., 2017).

Outro dado relevante é que o TEA é diagnosticado com uma frequência quatro vezes maior em meninos do que em meninas. Ademais, estudos indicam que 0 estresse perinatal e matrimonial aumenta o risco de autismo nas crianças, demonstrando também possuir um fator ambiental além do componente genético (CRITTENDEN, 2017; MANDY, 2016).

\subsection{Etiologia}

Apesar da causa exata não ter sido esclarecida, sabe-se que o TEA tem causa multifatorial, por fatores genéticos e ambientais. Existem evidências de que o autista herda genes com mutações e inversões, compreendendo múltiplos modelos de herança (ARAÚJO et al., 2019). 
Além do componente genético, a idade dos pais no momento da concepção, cuidados excessivos ou negligentes com a criança, utilização de medicamentos durante o período pré-natal, nascimento prematuro e o baixo peso ao nascer também podem influenciar (ARAÚJO et al., 2019).

\subsection{Fiopatologia}

Há uma disfunção do córtex cerebral associativo nos autistas, com alteração na conectividade entre os hemisférios cerebrais e zonas de pouca e muita conectividade, o que provoca dificuldade na assimilação das informações e na coordenação entre os diferentes sistemas neurais. Um dos motivos que contribuem para o quadro sintomático dos distúrbios do desenvolvimento neurológico, como o TEA e a esquizofrenia, é a interrupção do equilíbrio entre sinalização excitatória/ inibitória cerebral, sobretudo no córtex pré-frontal. Os comportamentos sociais demandam relação coordenada das regiões do cérebro e, consequentemente, anormalidades nessas regiões poderiam acarretar distúrbios do comportamento social (ALMEIDA et al., 2018).

Diversos mecanismos fisiopatológicos para o TEA estão sendo estudados além da herdabilidade genética e da epigenética, como a desregulação autoimune. Esse fator pode ser explicado pela hipótese de níveis anormais de citocinas e de fatores de crescimento, bem como anticorpos fetais e maternos encontrados no tecido cerebral do autista. Além disso, acredita-se que tenha um aumento do estresse oxidativo, disfunção mitocondrial, anormalidades na serotonina cerebral, conectividade anormal da substância branca, diminuição do número das células de Purkinje cerebelares e defeitos da migração neuronal. Apesar do avanço na fisiopatologia neurobiológica do TEA, ainda não existe um marcador específico para o diagnóstico (ORNOY, 2016).

\subsection{Manifestações clínicas}


A trajetória inicial do TEA não é constante. Isso se deve aos sintomas que em algumas crianças podem se manifestar logo após o nascimento, mas na maior parte dos indivíduos começam a ser mais aparentes entre 12 e 24 meses de idade. Outrossim, trata-se de um transtorno que se estende por toda a vida, não havendo cura definitiva. Porém, se houver intervenção precoce, melhor tende a ser o prognóstico e qualidade de vida do autista (ARAÚJO et al., 2019; ZWAIGENBAUM et al., 2015).

É importante se atentar às características do TEA, à perda de habilidades já adquiridas ou mudanças no comportamento da criança. Isso pode ser evidenciado com redução do contato visual; diminuição do sorriso social; sentimento de indiferença frente a emoções distintas; pouco interesse em pessoas; atraso no desenvolvimento da linguagem, por exemplo não pronunciar palavras até os dezesseis meses e não formar frases até os dois anos de idade; ecolalia (repetição de palavras ou frases que ouve); inexistência de retorno ao chamamento pelo nome; pouco discernimento quanto a gravidade de algumas situações e hiperresponsividade auditiva (HALPERN, 2015; ARAÚJO et al., 2019).

\subsection{Classificação e diagnóstico}

O predecessor do Manual Diagnóstico e Estatístico de Transtornos Mentais - $5^{\mathrm{a}}$ edição (DSM-V), o Manual Diagnóstico e Estatístico de Transtornos Mentais - $4^{a}$ edição (DSM-IV), incluia cinco Transtornos Globais do Desenvolvimento (TGDs): Transtorno do Autismo, Transtorno de Asperger, Transtorno Desintegrativo da Infância, Transtorno de Rett e Transtorno Global do Desenvolvimento Sem Outra Especificação (PDD-NOS) (A.P.A., 2016).

Já no DSM-V, o Transtorno do Autismo, Transtorno de Asperger e PDD-NOS são substituídos pelo diagnóstico unificado de TEA com diferentes níveis de gravidade. No DSM-V, o Transtorno de Rett encontra-se no diagnóstico diferencial por seus sintomas coincidirem com os sintomas do espectro autista, porém, os déficits da interação social que ocorre no Transtorno de Rett tendem a melhorar após os 4 anos 
de vida, não se caracterizando, desse modo, dentro do espectro autista (A.P.A., 2016). De acordo com a Organização Mundial da Saúde (OMS) ou World Health Organization (WHO), a $10^{a}$ edição da Classificação Internacional de Doenças (CID-10) também abrange designações separadas, do mesmo modo que o DSM-IV, tais como: Síndrome de Rett, de Asperger, Transtorno Desintegrativo da Infância e Pervasivo do Desenvolvimento Sem Outra Especificação.

\title{
1.6 Tratamento
}

Outro aspecto importante engloba os principais objetivos do tratamento, os quais foram ressaltados por Sadock (2017):

\begin{abstract}
"Os principais objetivos do tratamento de crianças com transtornos do espectro do autismo são focar em comportamentos básicos para melhorar a interação e a comunicação social; expandir estratégias de integração escolar; desenvolver relacionamentos significativos com os colegas; e aumentar as habilidades para viver uma vida independente a longo prazo. $O$ foco principal das intervenções psicoterapêuticas é ajudá-los a desenvolver habilidades em práticas sociais, trabalhar com colegas para estimular comportamentos socialmente aceitáveis e pró-sociais e diminuir estereotipias motoras (SADOCK, 2017. p.1161)".
\end{abstract}

O estímulo do aprendizado e desenvolvimento de aptidões cognitivas e sociais por meio de métodos de ensino, além de estratégias precoces baseadas em evidências e a capacitação de pais e cuidadores por profissionais treinados visam promover a neuroplasticidade. Dessa forma, estimula-se as sequências do desenvolvimento da criança (YOGMAN et al., 2018).

Para que o tratamento seja mais eficiente, é imprescindível que haja uma equipe multidisciplinar envolvendo: psicólogos, fonoaudiólogos, terapeutas ocupacionais, educador físico e o fisioterapeuta. Esses profissionais devem estimular diferentes habilidades como cognitiva, motora, social e da linguagem do autista (FERREIRA et al., 2016).

Segundo Soorya (2018), os métodos de intervenção que são utilizados para aprimorar o desenvolvimento de pessoas autistas são: 
- Sistema de comunicação por troca de imagens ou Picture Exchange Communication System (PECS): um método de comunicação alternativo com identificação, troca e discriminação de figuras;

- Análise de Comportamento Aplicado ou Applied Behavior Analysis (ABA): uma análise comportamental aplicada nos princípios fundamentais da teoria de aprendizagem para desenvolver habilidades de comunicação, interação social e vocacional e reduzir comportamentos indesejados.

- Modelo Baseado nas Relações, Diferenças Individuais e Desenvolvimento (DIR): inclui o Floortime ou terapia do tempo, os pais e os terapeutas seguem a liderança da criança ao brincarem e a dirigem para que progridam em atividades mais complexas gradativamente.

- Tratamento e Educação para Autistas e Crianças com Déficits Relacionados à Comunicação ou Treatment and Education of Autistic and related Communications Handicapped Children (TEACCH): promove o engajamento nas atividades, a independência e a educação por meio de técnicas com base nas dificuldades e aptidões em relação a aprendizagem da criança.

- Modelo Denver de Intervenção Precoce ou Early Start Denver Model (ESDM): baseado nos métodos da Terapia ABA, é voltado para as crianças de um a cinco anos e tem como objetivo trabalhar a comunicação receptiva e expressiva, habilidades sensoriais, competências motoras e comportamento adaptativo através de brincadeiras e jogos interpessoais para construir relações positivas.

O tratamento farmacológico deve ser prescrito pelo médico especialista e indicado quando existe alguma complicação neurológica e/ou psiquiátrica e quando os sintomas trazem algum prejuízo ao autista (AMORIM, 2021). No Brasil, apenas a risperidona e a periciazina possuem indicação em bula e recomendação pela Agência Nacional de Vigilância Sanitária (ANVISA) para sintomas-alvo no autismo, no entanto outros fármacos têm sido utilizados na prática clínica, com o objetivo de manter 
controle da agressividade, agitação, impulsividade, entre outros sintomas (NETO, 2019).

\subsection{Objetivos}

\subsubsection{Objetivo geral}

- Investigar a inserção da criança com Transtorno do Espectro Autista (TEA) no contexto escolar, familiar e social.

1.7. 2 Objetivos específicos

- Indagar a relação da criança autista com os professores e colegas de classe .

- Perguntar a respeito da relação da criança autista com a família e cuidadores.

- Questionar sobre o relacionamento da criança autista com a sociedade em geral.

\section{JUSTIFICATIVA}

Esta pesquisa visou reconhecer como se dá a inserção da criança autista na sociedade, por meio de um questionário on-line aplicado aos cuidadores sobre a percepção deles acerca da relação do autista com os pais, professores e profissionais que acompanham seu desenvolvimento.

O diferencial deste projeto encontra-se no modo como será desenvolvido, tendo em vista não só a criança com TEA, mas sim todos que participam de seu progresso. O motivo para pô-lo em prática é a contribuição social futura para famílias que apresentarem um portador de TEA, pois poderão saber mais sobre a inclusão do autista e, assim, auxiliar no seu desenvolvimento neuropsicomotor

\section{METODOLOGIA}


A presente pesquisa trata-se de uma investigação de natureza quantitativa e observacional. O projeto foi realizado por meio de um questionário on-line voltado aos pais e/ou cuidadores de crianças com TEA, integrantes de grupos de redes sociais, como WhatsApp e Facebook, sem vínculo com instituições. Foi utilizado o questionário de dificuldades comunicativas, sendo esse validado e adaptado de Balestro et al. (2012) ao nosso estudo.

O questionário abrangeu 25 questões objetivas dirigidas aos pais e/ou cuidadores em relação à percepção deles para com as crianças autistas (ANEXO 1). Os aspectos específicos abordados foram divididos em três domínios - sendo eles, ambiente escolar, familiar e social da criança. As perguntas abrangeram a impressão dos pais e/ou cuidadores em relação à criança, a percepção dos pais e/ou cuidadores em relação à aceitação das pessoas para com a criança e a atitude dos pais e/ou cuidadores para com a criança. Como critério de inclusão, a pesquisa foi destinada aos pais e/ou cuidadores que participam de grupos on-line sobre autistas nas redes sociais.

Para aplicação do questionário foi utilizada a escala tipo Likert, com a seguinte descrição: concordo completamente (CC) - quando há concordância dominante; concordo $(C)$ - quando há concordância predominante, porém nem todas as vezes; discordo (D) - quando há discordância predominante, porém nem todas as vezes; discordo completamente (DC) - quando há discordância dominante.

A coleta de dados foi efetuada nos meses de fevereiro e março de 2021. Para

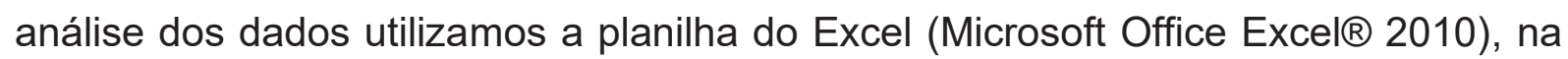
qual os dados foram transcritos e analisados formando um banco de dados para realização do nível de concordância das questões e a comparação dos referidos resultados dos domínios entre si. Todos os participantes assinaram um Termo de Consentimento Livre e Esclarecido (TCLE) que foi disponibilizado junto ao questionário, aceitando participar desta pesquisa.

\subsection{Dados coletados}


Tabela 1: Característica sobre a inserção da criança com Transtorno do Espectro Autista (TEA) no domínio escolar sob a ótica de seus pais e/ou cuidadores (2021).

\begin{tabular}{|c|c|c|c|c|c|}
\hline & Questão & $\operatorname{CC}^{1}\left(n^{0} / \%\right)^{*}$ & $\mathrm{C}^{2}\left(\mathrm{n}^{0} / \%\right)^{*}$ & $\mathrm{DC}^{3}\left(\mathrm{n}^{0} / \%\right)^{*}$ & $D^{4}\left(n^{\circ} / \%\right)^{*}$ \\
\hline & 1 & $40 / 48,8$ & 32 / 39 & $9 / 11$ & $1 / 1,2$ \\
\hline & 2 & $15 / 18,3$ & $31 / 37,8$ & $5 / 6,1$ & $31 / 37,8$ \\
\hline & 3 & $10 / 12,2$ & $23 / 28$ & $12 / 14,6$ & $37 / 40,1$ \\
\hline \multirow[t]{4}{*}{ Domínio escolar } & 4 & $7 / 8,5$ & $28 / 34,1$ & $11 / 13,4$ & $36 / 43,9$ \\
\hline & 5 & $8 / 9,8$ & $12 / 14,6$ & $22 / 26,8$ & $40 / 48,8$ \\
\hline & 6 & $5 / 6,1$ & $21 / 25,6$ & 19 / 23,2 & $37 / 45,1$ \\
\hline & 7 & $6 / 7,3$ & $13 / 15,9$ & $13 / 15,9$ & $50 / 61$ \\
\hline
\end{tabular}

Fonte: Produção própria (2021).

A pesquisa obteve um total de 82 respostas, que correspondem a $100 \%$.

${ }^{1} \mathrm{CC}$ : Concordo completamente; ${ }^{2} \mathrm{C}$ : Concordo; ${ }^{3} \mathrm{DC}$ : Discordo completamente; ${ }^{4} \mathrm{D}$ : Discordo. *(n०/\%): (número de respostas / porcentagem de respostas em relação ao total).

Tabela 2: Característica sobre a inserção da criança com Transtorno do Espectro Autista (TEA) no domínio familiar sob a ótica de seus pais e/ou cuidadores (2021).

\begin{tabular}{|c|c|c|c|c|c|}
\hline & Questão & $\operatorname{CC}^{1}\left(n^{0} / \%\right)^{*}$ & $\mathrm{C}^{2}\left(\mathrm{n}^{0} / \%\right)^{*}$ & $\mathrm{DC}^{3}\left(\mathrm{n}^{\circ} / \%\right)^{*}$ & $D^{4}\left(n^{\circ} / \%\right)^{*}$ \\
\hline & 8 & $3 / 3,7$ & 22 / 26,8 & $13 / 15,9$ & $44 / 53,7$ \\
\hline & 9 & $7 / 8,5$ & $31 / 37,8$ & $10 / 12,2$ & $34 / 41,5$ \\
\hline & 10 & $31 / 37,8$ & $47 / 57,3$ & $4 / 4,9$ & $0 / 0$ \\
\hline & 11 & $7 / 8,5$ & $28 / 34,1$ & $18 / 22$ & $29 / 35,4$ \\
\hline \multirow[t]{5}{*}{ Domínio familiar } & 12 & $16 / 19,5$ & $38 / 46,3$ & $6 / 7,3$ & $22 / 26,8$ \\
\hline & 13 & $13 / 15,9$ & $48 / 58,5$ & $3 / 3,7$ & $18 / 22$ \\
\hline & 14 & $8 / 9,8$ & $41 / 50$ & $6 / 7,3$ & $27 / 32,9$ \\
\hline & 15 & $5 / 6,1$ & $35 / 42,7$ & $5 / 6,1$ & 37 / 45, 1 \\
\hline & 16 & $5 / 6,1$ & $22 / 26,8$ & $15 / 18,3$ & $40 / 18,8$ \\
\hline
\end{tabular}

Fonte: Produção própria (2021).

A pesquisa obteve um total de 82 respostas, que correspondem a $100 \%$.

${ }^{1} \mathrm{CC}$ : Concordo completamente; ${ }^{2} \mathrm{C}$ : Concordo; ${ }^{3} \mathrm{DC}$ : Discordo completamente; ${ }^{4} \mathrm{D}$ : Discordo. ${ }^{*}\left(n^{\circ} / \%\right)$ : (número de respostas / porcentagem de respostas em relação ao total). 
Tabela 3: Característica sobre a inserção da criança com Transtorno do Espectro Autista (TEA) no domínio social sob a ótica de seus pais e/ou cuidadores (2021).

\begin{tabular}{lccccc}
\hline & Questão & $\mathbf{C C}^{\mathbf{1}}\left(\mathbf{n}^{\mathbf{0}} / \%\right)^{*}$ & $\mathbf{C}^{\mathbf{2}}\left(\mathbf{n}^{\mathbf{0}} / \%\right)^{*}$ & $\mathbf{D C}^{\mathbf{3}}\left(\mathbf{n}^{\mathbf{0}} / \%\right)^{*}$ & $\mathbf{D}^{\mathbf{4}}\left(\mathbf{n}^{\mathbf{0}} / \%\right)^{*}$ \\
\hline & 17 & $5 / 6,1$ & $33 / 40,2$ & $10 / 12,2$ & $34 / 41,5$ \\
& 18 & $20 / 24,4$ & $52 / 63,4$ & $3 / 3,7$ & $7 / 8,5$ \\
Domínio social & 19 & $16 / 19,5$ & $35 / 42,7$ & $3 / 3,7$ & $28 / 34,1$ \\
& 20 & $21 / 25,6$ & $47 / 57,3$ & $2 / 2,4$ & $12 / 14,6$ \\
& 21 & $20 / 24,4$ & $42 / 51,2$ & $3 / 3,7$ & $17 / 20,7$ \\
& 22 & $14 / 17,1$ & $32 / 39$ & $7 / 8,5$ & $29 / 35,4$ \\
& 23 & $10 / 12,2$ & $37 / 45,1$ & $12 / 14,6$ & $23 / 28$ \\
& 24 & $17 / 20,7$ & $49 / 59,8$ & $5 / 6,1$ & $11 / 13,4$ \\
& 25 & $66 / 80,5$ & $15 / 18,3$ & $0 / 0$ & $1 / 1,2$ \\
\hline
\end{tabular}

Fonte: Produção própria (2021).

A pesquisa obteve um total de 82 respostas, que correspondem a $100 \%$.

${ }^{1} \mathrm{CC}$ : Concordo completamente; ${ }^{2} \mathrm{C}$ : Concordo; ${ }^{3} \mathrm{DC}$ : Discordo completamente; ${ }^{4} \mathrm{D}$ : Discordo. *(no/\%): (número de respostas / porcentagem de respostas em relação ao total).

\section{RESULTADOS}

Com relação aos pontos apresentados, o questionário foi dividido em três domínios contemplados nas tabelas 1, 2 e 3. As tabelas expõem dados em relação ao domínio escolar, familiar e social, que foram coletados por meio de um questionário composto por 25 questões objetivas com quatro alternativas, em que uma única alternativa deveria ser escolhida pelo participante. As alternativas eram compostas por 4 opções de resposta: CC - concordo completamente; C - concordo; DD - discordo completamente e D - discordo.

As questões foram respondidas com base na impressão dos pais ou cuidadores em relação às crianças com TEA. Os domínios contemplaram $28 \%$ de questões em relação à inclusão escolar (7 questões), 36\% sobre a familiar (9 questões) e $36 \%$ quanto ao aspecto social ( 9 questões). O questionário foi respondido por 82 pais e/ou cuidadores de crianças com TEA. Essas respostas foram agrupadas nas tabelas apresentadas anteriormente, em que cada questão enumerada de 1 a 25 corresponde às 25 perguntas contidas no questionário (ANEXO 1). Cada questão exposta nas tabelas apresenta o número de respostas $\left(n^{\circ}\right)$ e a porcentagem de respostas $(\%)$ em cada alternativa (CC; C; DC; D) tendo em consideração as 82 respostas totais assinaladas pelas participantes. 
Alguns resultados demonstraram concordância mais expressiva, como a impressão que os pais ou cuidadores têm de que as crianças possuem poucos amigos (87,8\% das respostas). Outra questão em que a concordância se mostrou majoritária $(95,1 \%)$ foi a de que os pais ou cuidadores conversam com as crianças mesmo que elas não conversem com eles. Além disso, a maioria dos pais ou cuidadores $(74,4 \%)$ relatam não saber lidar com alguns comportamentos das crianças.

Outro ponto relevante é que os pais e cuidadores referem, em sua maioria $(82,9 \%)$, que as crianças fazem ou falam coisas que não têm relação com o momento e o assunto. Ademais, para a grande maioria dos pais ou cuidadores $(85,6 \%)$ outras pessoas estranham ou evitam as crianças. Um outro aspecto importante é que a maioria dos pais e cuidadores $(80,5 \%)$ concorda que as crianças ficam agitadas em lugares públicos. Por fim, é válido destacar que a imensa maioria dos pais ou cuidadores $(98,8 \%)$ responderam que a sociedade possui poucas informações sobre como se relacionar socialmente com um indivíduo autista.

Outros resultados demonstraram discordância prevalente, por exemplo a questão que grande parte de pais e cuidadores discorda sobre as crianças não gostarem de ir para a escola ( $75,6 \%$ das respostas). Ademais, a maioria dos pais e cuidadores $(68,3 \%)$ discordam que as crianças não apresentam um bom desenvolvimento escolar.

Além disso, os pais e cuidadores em sua maioria $(76,9 \%)$ discordam que as crianças se desenvolvem melhor em matérias teóricas que práticas. Outro fator relevante é que a maior parcela de pais e cuidadores discorda que as crianças não compreendem o que eles dizem (69,6\%). Para finalizar, um outro ponto importante é que a maior parte dos pais e cuidadores $(67,1 \%)$ discorda que eles têm dificuldade em brincar com a criança.

\section{DISCUSSÃO}

O questionário aplicado foi utilizado como instrumento de coleta de dados que abordou temas pessoais e gerais relacionados ao TEA. Os domínios utilizados foram 
embasados na inter-relação das crianças com TEA quanto aos demais com quem têm contato.

O primeiro domínio engloba a inclusão escolar do autista, por exemplo, no âmbito social, com os colegas de classe e no disciplinar, com os professores. Ademais, o segundo domínio se baseou no relacionamento da criança com o núcleo familiar, abrange como ocorre a relação, comunicação e comportamento entre pai/cuidador e criança com TEA. As questões que dizem respeito ao terceiro e último domínio, área social, incluem como a criança é tratada pelas pessoas a sua volta e como ela interage com esfera social em que está inserida

Uma das características das crianças autistas é que elas tendem a ser mais introspectivas e se isolarem socialmente, dependendo do grau de acometimento do transtorno podem, inclusive, ter um desenvolvimento disfuncional da comunicação, o que compromete a interação com outras pessoas (BLANCHE et al., 2015). Esse fato justifica o resultado encontrado de que pais ou cuidadores relatam que as crianças possuem poucos amigos, porque há uma tendência de serem introspectivas. Constantemente, as crianças com TEA se interessam por si próprios, assim, costumam dirigir a atenção para o próprio corpo, inclusive durante as brincadeiras (SANTOS, 2018).

Ademais, o aspecto de que pais ou cuidadores conversam com as crianças portadoras de TEA mesmo que não seja algo recíproco é muito importante para o desenvolvimento de habilidades comunicativas, motoras, cognitivas e sociais dessas crianças. Os estímulos parentais ao invés de atitudes permissivas, de excessiva proteção das crianças, contribuem favoravelmente para evolução dessas aptidões (FRYE, 2016).

É muito comum déficits motores e sensoriais em indivíduos com TEA. Umas das condutas que envolvem conjunto de estímulos sensórios às respostas apropriadas são os tratamentos passivos e ativos, que ajudam no melhorar o prognóstico do transtorno. O passivo inclui a orientação pelo terapeuta em relação aos movimentos do autista, e o ativo o envolve em atividades que fornecem informações sensoriais (WHITMAN, 2015). 
Outro ponto interessante, é que pais ou cuidadores afirmam não saber lidar com alguns comportamentos das crianças com TEA, além de que elas podem fazer ou falar coisas que não tem relação com o momento ou assunto, conforme os dados coletados nesta pesquisa. Esse ponto pode ser correlacionado à dificuldade de empatia cognitiva pelo autista, a qual significa que eles não conseguem ver o mundo sob a ótica de pessoas neurotípicas e por isso agem de forma diferente frente às situações e assuntos, pois muitas vezes não entendem a linguagem não-verbal, como expressões faciais, gestos e tom de voz (REIS, 2017).

Vale salientar que a empatia cognitiva não deve ser confundida com a empatia emocional, pois esta compreende o sentimento de compaixão em relação aos outros indivíduos frente a uma adversidade, o qual normalmente está presente em crianças autistas (REIS, 2017).

A imaginação ou compreensão do ponto de vista de outros indivíduos ou a formação da autorrepresentação da realidade é denominada, no campo de estudo da cognição, de teoria da mente. Esta pode estar ausente nas pessoas com TEA e, por consequência, geram as características de alterações cognitivas dos autistas (ALMEIDA et al., 2018).

Pode-se acrescentar ainda, o fato de que as crianças ficam agitadas em lugares públicos, pois não se sentem à vontade quando estão com pessoas que não fazem parte de seu convívio habitual. Por esse motivo é importante o contato físico afetivo por parte das pessoas que convivem com as crianças, de modo a incentivá-las a desenvolverem comportamentos que evitem o isolamento e estimulem relações sociais (BEZERRA, 2021).

Além disso, pode-se adicionar às questões anteriores, a vertente sobre pais e cuidadores afirmarem que as pessoas estranham e evitam as crianças autistas. Tal afirmativa corrobora com o fato de a sociedade possuir poucas informações sobre como se relacionar socialmente com indivíduos autistas. Isso constitui, muitas vezes, um ato de preconceito que advém de pessoas neurotípicas se sentirem incomodadas pela presença dos autistas (MOITA et al., 2018). Outro ponto a se ressaltar é que, 
infelizmente, as crianças com TEA são vulneráveis a provocações e ao bullying (SWAIMAN et al., 2017).

O prejulgamento pode fazer com que os pais ou cuidadores ajam de maneira superprotetora com as crianças, deixando de lado os estímulos imprescindíveis para seu desenvolvimento social. Faz-se extremamente necessário que apesar de olhares preconceituosos da sociedade, os estímulos do desenvolvimento para a inserção social dessas crianças sejam praticados habitualmente a fim de superar o estigma que está presente (MOITA et al., 2018).

Um aspecto a ser ressaltado é que a Política Nacional de Educação na Perspectiva da Educação Inclusiva (BRASIL, 2008) e a Política Nacional de Proteção dos Direitos da Pessoa com TEA (BRASIL, 2012) asseguram-Ihes educação inclusiva. Segundo o Decreto № 8.364/2014, é direito da pessoa com TEA o acesso à educação, em sistema educacional inclusivo e transversal até o ensino superior e é dever do Estado, família, sociedade e comunidade escolar garanti-lo.

Desse modo, o ingresso de uma criança autista em escola regular é um direito assegurado por lei. No entanto, também é essencial garantir que esses alunos continuem na escola, com acesso a oportunidades e meios para sua aprendizagem. Para tal fim, é imprescindível a preparação da escola para recebê-los. Diante do exposto, é de suma importância conhecer por completo o transtorno e avaliar que mudanças necessitam ser realizadas para incluir de fato tais alunos (COSTA, 2017).

Ainda com relação ao contexto educacional percebe-se pelas questões respondidas que os autistas em sua maioria gostam de ir à escola, além de apresentarem bom desenvolvimento escolar majoritariamente, principalmente em matérias práticas. É válido salientar que o aluno com TEA, mesmo com suas dificuldades, tem a capacidade de aprender, pois é uma característica inerente ao ser humano. Essa aprendizagem depende de um ensino eficaz para obter o conhecimento final por meio de diálogos objetivos que facilitam o entendimento do autista (CUNHA, 2015).

Outrossim, um fator que tange ao processo de inclusão familiar, diz respeito às questões sobre as crianças com TEA compreenderem o que dizem os pais e 
cuidadores, além de eles não possuírem dificuldade em brincar com os autistas, em sua maioria. É mister salientar que essa parceria familiar, além da escolar e social, faz-se essencial para que os autistas alcancem o nível e qualidade de envolvimento indispensáveis para garantir o adequado desenvolvimento e inclusão dessas crianças (OLIVEIRA, 2015).

No âmbito de tratamento multidisciplinar é muito importante que o profissional tenha conhecimento acerca do TEA, sua patologia e de sua terapêutica. Assim, fazse necessário a função da fisioterapia no acompanhamento do paciente com TEA, visando o desenvolvimento motor, ativando áreas de concentração e da relação social (FERREIRA et al., 2016).

\section{CONSIDERAÇÕES FINAIS}

Por meio dessa pesquisa foi possível verificar vários pontos relevantes sobre a inclusão escolar, familiar e social da criança com TEA pela ótica dos pais e/ou cuidadores. Assim, percebe-se que ainda falta um avanço sobre o tema na sociedade e uma maior necessidade de divulgação de informações sobre o transtorno, como forma de conscientizar e aumentar a inserção dessas pessoas socialmente.

Destarte, com mais conhecimento e compressão sobre o tema será possível quebrar os preconceitos e paradigmas ainda vistos na sociedade com relação aos autistas. Por conseguinte, a aquisição de informações em relação às crianças com TEA melhoraria seu desenvolvimento neuropsicomotor através de sua inclusão.

Com este estudo, espera-se ter contribuído com a comunidade em geral, que possui familiares ou pessoas próximas autistas e com a sociedade científica, especialmente na área da Neuropsicologia e da Psicologia do Desenvolvimento. Ademais, essa pesquisa visa incentivar a inclusão da criança com TEA nos âmbitos escolar, familiar e social integralmente. 


\section{REFERÊNCIAS}

ALMEIDA, Simone Saraiva de Abreu et al. Transtorno do Espectro Autista - Sociedade Brasileira de Pediatria (SBP). Residência Pediátrica, 2018.

AMORIM, Letícia Calmon Drummond. Tratamento. AMA - Associação de Amigos do Autista. 2021. Disponível em https://www.ama.org.br/site/autismo/tratamento/. Acesso em: maio de 2021.

A.P.A - AMERICAN PSYCHIATRIC ASSOCIATION. Diagnostic and statistical manual of mental disorders. Supplement for Fifth edition, 2016.

ARAÚJO, Liubiana Arantes de et al. Transtorno do Espectro do Autismo. Manual de Orientação do Departamento Científico de Pediatria do Desenvolvimento e Comportamento - Sociedade Brasileira de Pediatria (SBP), n. 5, 2019.

BALESTRO, Juliana Izidro et al. Questionário sobre dificuldades comunicativas percebidas por pais de crianças do espectro do autismo. Revista da Sociedade Brasileira de Fonoaudiologia, 2012.

NETO, Sebastião Gonçalves de Barros; BRUNONI, Decio; CYSNEIROS, Roberta Monterazzo. Abordagem psicofarmacológica no transtorno do espectro autista: uma revisão narrativa. Cadernos de Pós-Graduação em Distúrbios do Desenvolvimento, v. 19, n. 2, p. 38-60, 2019.

BEZERRA, Giovani Ferreira et al. Política nacional de educação especial na perspectiva da educação inclusiva: por uma (auto) crítica propositiva. Roteiro, v. 46, n. 1, p. 1-26, 2021.

BLANCHE, Erna Imperatore et al. Caregiving experiences of Latino families with children with autism spectrum disorder. American Journal of Occupational Therapy, v. 69, n. 5, p. 6905185010p1-6905185010p11, 2015.

COSTA, Fihama Brenda Lucea da. 0 processo de inclusão do aluno autista na escola regular: análise sobre as práticas pedagógicas. 2017. Trabalho de Conclusão de Curso. Universidade Federal do Rio Grande do Norte.

CRITTENDEN, Patricia M. Formulating autism systemically: part 1 - a review of the published literature and case assessments. Clinical Child Psychology And Psychiatry, [S.L.], v. 22, n. 3, p. 378-389, jul. 2017.

CUNHA, Graciele Rodrigues da; BORDINI, Daniela; CAETANO, Sheila Cavalcante. Autismo, transtorno do espectro do autismo. CAETANO, Sheila; VICENTE, Renata; NOGUEIRA, Priscila; LIMA-HERNANDES, Maria Célia, p. 13-24, 2015.

FERREIRA, Jackeline Tuan Costa et al. Efeitos da fisioterapia em crianças autistas: estudo de séries de casos. Cadernos de Pós-Graduação em Distúrbios do Desenvolvimento, v. 16 , n. 2, p. 24-32, 2016. 
FRYE, Linda. Fathers' experience with autism spectrum disorder: Nursing implications. Journal of Pediatric Health Care, v. 30, n. 5, p. 453-463, 2016.

GOMES, Paulyane TM et al. Autismo no Brasil, desafios familiares e estratégias de superação: revisão sistemática. Jornal de pediatria, v. 91, n. 2, p. 111-121, 2015.

HALPERN, R. Manual de pediatria do desenvolvimento e comportamento. São Paulo: $\mathbf{1}^{\mathbf{a}}$ edição Manole, 2015.

Lei no 12.764, de 27 de dezembro de 2012. Institui a Política Nacional de Proteção dos Direitos da Pessoa com Transtorno do Espectro Autista, 2012.

LYALL, Kristen et al. The changing epidemiology of autism spectrum disorders. Annual review of public health, v. 38, p. 81-102, 2017.

MANDY, William; LAI, Meng-Chuan. Annual Research Review: the role of the environment in the developmental psychopathology of autism spectrum condition. Journal Of Child Psychology And Psychiatry, [S.L.], v. 57, n. 3, p. 271-292, 19 jan. 2016.

MOITA, Carina Estrela et al. AUTISMO: inclusão sem preconceito. REVISTA DE TRABALHOS ACADÊMICOS-UNIVERSO SALVADOR, v. 1, n. 6, 2018.

OLIVEIRA, Andréia Cosme de. O papel da família no processo de inclusão escolar do aluno com Transtorno do Espectro Autista. 2015.

ORNOY, Asher; WEINSTEIN-FUDIM, Liza; ERGAZ, Zivanit. Genetic syndromes, maternal diseases and antenatal factors associated with autism spectrum disorders (ASD). Frontiers in neuroscience, v. 10, p. 316, 2016.

Política Nacional de Educação Especial na Perspectiva da educação Inclusiva. Brasília, MEC/SEESP, 2008.

REIS, Samara Passos Santos. Empatia afetiva e cognitiva e o fenótipo ampliado do autismo: Adaptação Transcultural e Validação de Medidas. 2017.

SADOCK, Benjamin J.; SADOCK, Virgínia A; RUIZ, Pedro. Compêndio de Psiquiatria: Ciências do Comportamento e Psiquiatria Clínica. 11.ed. Porto Alegre: Artmed, 2017.

SANTOS, Évelyn Crys Farias dos; MÉLO, Tainá Ribas. Caracterização psicomotora de criança autista pela escala de desenvolvimento motor. Divers@!, v. 11, n. 1, p. 50-58, 2018.

SOORYA, L.; CARPENTER, L.; EL-GHOROURY, N. Diagnosing and managing autismo. American Psichological Association, 2018.

SWAIMAN, Kenneth F. et al. Swaiman's Pediatric Neurology E-Book: Principles and Practice. Elsevier Health Sciences, 2017 WHO (org.). International Statistical Classification of Diseases and Related Health Problems 10th Revision. 2019. Disponível em: https://icd.who.int/browse10/2019/en. Acesso em: maio de 2021. 
WHITMAN, Thomas L. O desenvolvimento do autismo: social, cognitivo, linguístico, sensório-motor e perspectivas biológicas. São Paulo: M. Books do Brasil Editora Ltda, v. 2, 2015.

YOGMAN, Michael et al. O poder da brincadeira: um papel pediátrico na promoção do desenvolvimento de crianças pequenas. Pediatrics, v. 142, n. 3, 2018.

ZWAIGENBAUM, Lonnie et al. Identificação precoce do transtorno do espectro do autismo: recomendações para prática e pesquisa. Pediatrics , v. 136, n. Suplemento 1, pág. S10S40, 2015.

\section{ANEXO 1 - QUESTIONÁRIO DE DIFICULDADES COMUNICATIVAS}

\begin{tabular}{|l|l|l|l|l|}
\hline QUESTÃO & CONCORDO & $\begin{array}{l}\text { CONCORDO } \\
\text { COMPLETAMENTE }\end{array}$ & DISCORDO & $\begin{array}{l}\text { DISCORDO } \\
\text { COMPLETAMENTE }\end{array}$ \\
\hline $\begin{array}{l}\text { 1. Eu tenho a impressão de } \\
\text { que a criança tem poucos } \\
\text { amigos (E) }\end{array}$ & & & \\
\hline $\begin{array}{l}\text { 2. Eu percebo que a criança } \\
\text { não gosta de se relacionar } \\
\text { com os colegas de classe (E) }\end{array}$ & & & & \\
\hline $\begin{array}{l}\text { 3. Eu percebo que os colegas } \\
\text { de classe não gostam de se } \\
\text { relacionar com a criança (E) }\end{array}$ & & & & \\
\hline $\begin{array}{l}\text { 4. Eu percebo que a criança } \\
\text { tem dificuldade de se } \\
\text { relacionar com os professores } \\
\text { (E) }\end{array}$ & & & & \\
\hline $\begin{array}{l}\text { 5. Eu tenho impressão de que } \\
\text { a criança não gosta de ir para } \\
\text { a escola (E) }\end{array}$ & & & & \\
\hline $\begin{array}{l}\text { 6. Eu acredito que a criança } \\
\text { não apresenta um bom } \\
\text { desenvolvimento escolar (E) }\end{array}$ & & & & \\
\hline $\begin{array}{l}\text { 7. Eu percebo que a criança se } \\
\text { desenvolve melhor em } \\
\text { matérias teóricas do que } \\
\text { práticas (E) }\end{array}$ & & & & \\
\hline $\begin{array}{l}\text { 8. Eu tenho a impressão de } \\
\text { que a criança não compreende } \\
\text { o que eu digo (F/S) }\end{array}$ & & & & \\
\hline $\begin{array}{l}\text { 9. Eu tenho dificuldade em } \\
\text { entender o que a criança diz }\end{array}$ & & & & \\
\hline
\end{tabular}




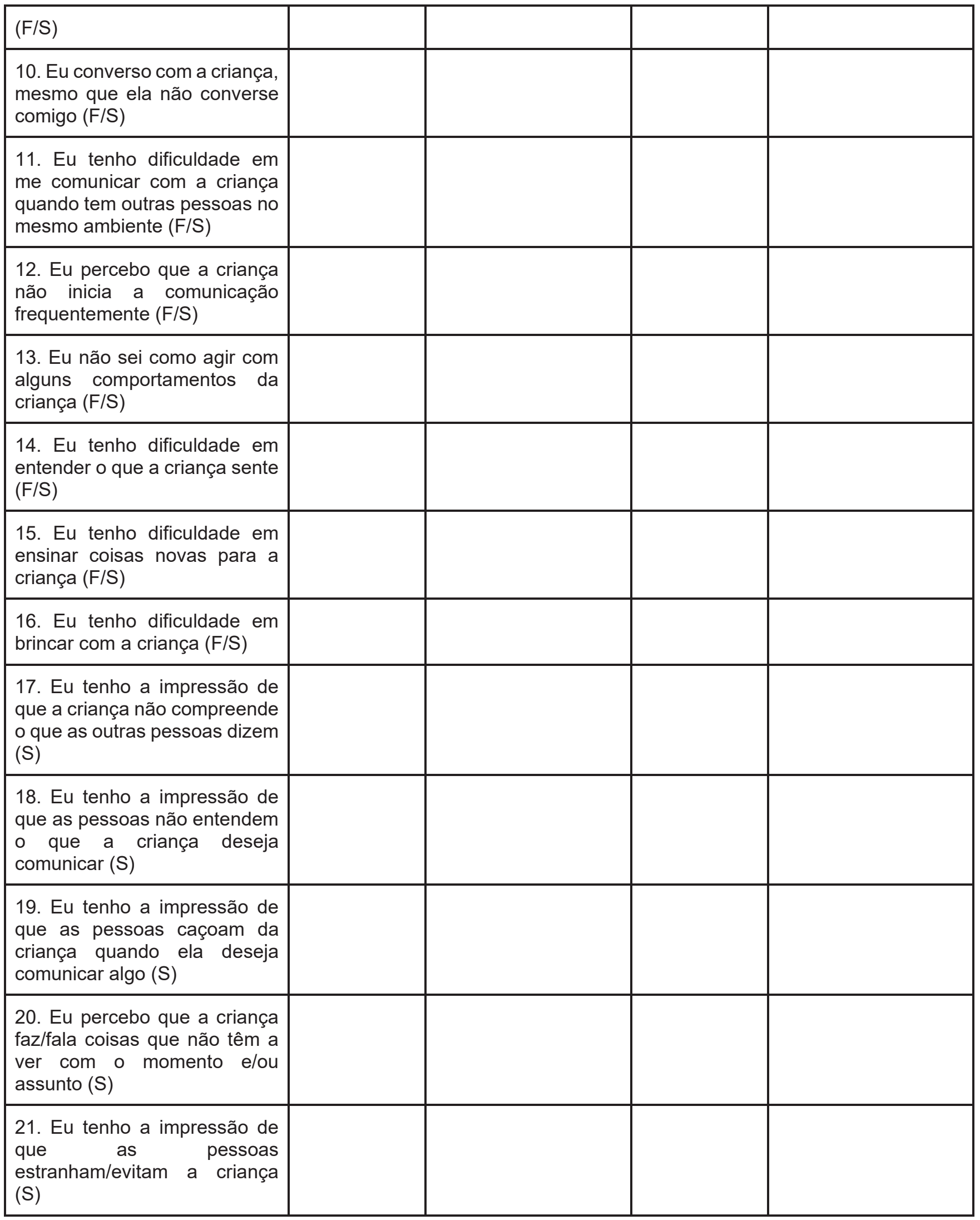




\begin{tabular}{|l|l|l|l|l|}
\hline $\begin{array}{l}\text { 22. Eu percebo que a criança } \\
\text { não se sente à vontade em } \\
\text { lugares públicos (S) }\end{array}$ & & & & \\
\hline $\begin{array}{l}\text { 23. Eu percebo que a criança } \\
\text { se apresenta introspectiva em } \\
\text { lugares públicos (S) }\end{array}$ & & & & \\
\hline $\begin{array}{l}\text { 24. Eu percebo que a criança } \\
\text { se apresenta agitada em } \\
\text { lugares públicos (S) }\end{array}$ & & & & \\
\hline $\begin{array}{l}\text { 25. Eu acredito que a } \\
\text { sociedade tem poucas } \\
\text { informações sobre como se } \\
\text { relacionar socialmente com um } \\
\text { indivíduo autista (S) }\end{array}$ & & & & \\
\hline
\end{tabular}

Fonte: adaptado (BALESTRO et al., 2012)

(E) - Pergunta em relação à escola

(F) - Pergunta em relação à família

(S) - Pergunta em relação à sociedade 